\title{
EMBARGO SOBRE DERECHOS SOCIALES
}

\author{
Roberto Medina Infante \\ Profesor de Práctica Forense \\ Universidad Católica del Norte \\ Sede Coquimbo
}

Prescribe el Artículo 2096 del Código Civil que "Los acreedores de un socio no tienen acción sobre los bienes sociales sino por hipoteca anterior a la sociedad, o por hipoteca posterior, cuando el aporte del inmueble no conste por inscripción en el competente Registro.

Podrán, sin embargo, intentar contra la sociedad las acciones indirecta y subsidiaria que se le conceden por el artículo 2094.

Podrán también pedir que se embarguen a su favor las asignaciones que se hagan a su deudor por cuenta de los beneficios sociales o de sus aportes o acciones."

Por su parte, el artículo 380 del Código de Comercio señala que: "Los acreedores personales de un socio no podrán embargar durante la sociedad el aporte que éste hubiere introducido; pero les será permitido solicitar la retención de la parte de interés que en ella tuviere para percibirla al tiempo de la división social.

Tampoco podrán concurrir en la quiebra de la sociedad con los acreedores sociales; pero tendrán derecho para perseguir la parte que corresponda a su deuda en el residuo de la masa concursada."

Estas, a mi juicio, son las disposiciones básicas que fijan las reglas del juego en materia de los derechos de los acreedores respecto de sociedades, ubicadas, la primera en las normas "De la sociedad" de los artículos 2053 y siguientes del Código Civil y la segunda, en el título del mismo nombre en lo referente a la "Sociedad Colectiva", artículos 348 y siguientes del Código de Comercio.

La ubicación de estos artículos en cada uno de los códigos indicados nos lleva a dejar constancia que, dado el carácter subsidiario del Código Civil, las disposiciones del artículo 2096 se aplican tanto a las sociędades comerciales, (sean colectivas, de responsabilidad limitada o en comanditas con respecto a los socios gestores), cuanto a las civiles, en tanto que las del artículo 380 del Código de Comercio, sólo a las comerciales, dado que estas disposiciones no son subsidiarias de las del Código Civil.

¿Cuál es el problema relacionado con este tema, sobre todo teniendo presente que los derechos que el deudor tiene en una sociedad forman parte de su Patrimonio, respecto del cual los acreedores tienen en su favor el "derecho de prenda general' consagrado en el artículo 2.465 del Código Civil? 
La inquietud tiene su origen, por una parte, en que no he observado un tratamiento preciso del tema en las numerosas obras que he consultado y que, por la otra, no hay jurisprudencia detallada sobre los varios aspectos jurídicos sobre la materia.

Por ello, vamos al análisis de nuestra preocupación:

Primero: Delimitación del tema: Como muy bien lo indica don Gabriel Palma Rogers, en su obra Derecho Comercial, (Imprenta Chile, año 1928, página 183), "No pueden embargar los derechos que los socios tengan en la sociedad, por tratarse de una sociedad colectiva que, como sabemos, es sociedad de personas; si tal cosa se permitie$\mathrm{ra}$, cualquier acreedor personal de un socio podrá adquirir los derechos de éste y pasar por este hecho a ser socio de la sociedad. Esta situación es muy diversa en las sociedades de capitales, en las que se puede sacar a remate las acciones de un socio y el rematante pasa así a ser, por su parte, socio de esas sociedades." En igual sentido se pronuncian los profesores señores Arturo Alessandri Rodríguez y Manuel Somarriva Undurraga, en el compendio preparado por don Antonio Vodanovic H. (Editorial Nascimento, años 1939-42, Tomo IV, páginas 529 y siguientes).

Tanto por la ubicación de los preceptos legales que limitan la acción de los acreedores en materia de embargo de derechos sociales, (sociedades civiles y colectivas comerciales), y la naturaleza de éstas, de carácter "intuito personae", nos llevan a la consideración que en las sociedades de capital no existen las limitaciones a la libre acción de los acreedores respecto del patrimonio del deudor puestas por el Legislador para las de personas. En este mismo criterio, la Ley 3.918 de 14 de Marzo de 1923, "sobre sociedades de responsabilidad limitada", al remitirse a las disposiciones del artículo 2104 del Código Civil y 455 y 456 del Código de Comercio, nos indica a las claras que las mismas razones de limitación al derecho de prenda general del acreedor se aplican a este tipo de sociedades.

Como primera conclusión tenemos que el problema se presenta sólo en las sociedades de persona y no en las de capital:

Segundo: Distinción necesaria: Don Enrique Munita Becerra, en el trabajo respecto de la "Embargabilidad del derecho social de un socio en una sociedad de personas, por un acreedor personal suyo", que comentaremos más adelante, hace una distinción que nos parece necesaria:

1.- $\quad$ El derecho social de un socio en la sociedad a que pertenece;

2.- Los beneficios, asignaciones, dividendos, etc., a que tenga derecho en la sociedad, provenientes de utilidades legítimamente obtenidas y comprobadas en un ejercicio o en la gestión social; y

3.- $\quad$ El aporte hecho en la sociedad por los socios que la componen:

Tercero: Características de la limitación: De la lectura y comparación de los textos de los Códigos Civil y Comercio, podemos deducir que las limitaciones puestas al ejercicio "normal" de los derechos del acreedor respecto de los bienes del deudor presentan semejanzas y disimilitudes en ambas recopilaciones.

a) Similitudes: En ambos textos se establece que "los acreedores de un socio no tienen acción sobre los bienes sociales...", (inciso primero del artículo 2096), y que "los 
acreedores personales de un socio no podrán embargar durante la sociedad el aporte que éste hubiere introducido", (inciso primero del artículo 380).

Estas limitaciones son lógicas ya que, desde el momento en que el aporte efectuado por un socio se ha gestionado observando la tramitación legal, deja de ser de su dominio pasando a ser bien social.

Hemos hecho hincapié en la frase "observando la tramitación legal" ya que mientras ésta no se complete, como sería, por ejemplo, que no se hubiere efectuado la competente inscripción del inmueble en el Registro de Propiedad del Conservador de Bienes Raíces, éste permanece en el patrimonio del socio aportante.

En ese mismo sentido razona el Legislador en el inciso primero del artículo 2096 al indicar que la posibilidad del acreedor de tener acción sobre un bien raíz está en el caso de "hipoteca, anterior a la sociedad, o por hipoteca posterior, cuando el aporte del inmueble no conste por inscripción en el competente Registro"; y

b) Disimilitudes: El inciso tercero del artículo 2096 permite que los acreedores puedan pedir "que se embarguen, a su favor las asignaciones que se hagan a su deudor por cuenta de los beneficios sociales o de sus aportes o acciones."

En cambio, el artículo 380 indica que: "Los acreedores personales de un socio no podrán embargar durante la sociedad el aporte que éste hubiere introducido; pero les será permitido solicitar la retención de la parte de interés que en ella tuviere para percibirla al tiempo de la división social."

Como podrá observarse, el Código Civil permite expresamente el embargo de las asignaciones que se hagan al deudor por cuenta de los beneficios sociales o de sus aportes 0 acciones. Da la impresión que basta sólo trabar el embargo para, sin remate de ninguna especie, el acreedor pueda percibir las asignaciones que se hagan... de los beneficios sociales 0 de sus aportes 0 acciones. Pensamos así porque, de igual manera, se procede en el caso de embargo de saldos de cuentas corrientes, de depósitos a plazo, de cantidades a percibir por el deudor que se encuentran en manos de terceros, etc.

En contraposición, el Código de Comercio es explícito en indicar que no se permite el embargo pero que, no obstante, a los acreedores les será permitido solicitar la retención de la parte de interés que en ella tuviere para percibirla al tiempo de la división social."

La primera de las disposiciones permite el embargo de las asignaciones que se hagan al deudor. ¿Pero, cómo el acreedor hace efectivo su crédito? ¿Necesita remate? En ausencia de texto expreso, nos da la impresión que el administrador de la sociedad debe ser notificado por el Tribunal, en el sentido de hacer llegar a éste las asignaciones que se hagan al deudor por cuenta de los beneficios sociales o de sus aportes o acciones.

La segunda de las disposiciones prohibe expresamente el embargo, pero el acreedores podrá solicitar la retención, para percibirla al tiempo de la división social. En este caso, el acreedor deberá esperar el vencimiento del plazo del contrato de sociedad.

Cuarto: Características de la inembargabilidad: Debemos tener presente que la norma común es la de la "prenda general" que tienen los acreedores sobre los bienes del 
deudor y que la "excepción" la constituye la inembargabilidad, la que, por ser excepcional, debe interpretarse restrictivamente.

Ahora bien, la restricción no necesariamente debe ser en términos sacramentales, sino en cualesquier forma que no deje dudas de la intención del Legislador.

Ahora, queda claro que no se permite el embargo del aporte introducido por un socio, (artículo 380), como tampoco sobre los bienes sociales, (artículo 2096). Procede sobre "las asignaciones que se hagan al deudor por cuenta de los beneficios sociales o de sus aportes o acciones", (artículo 2096), y la retención, que para estos efectos equiparamos al embargo, sobre la parte del interés social que en ella tuviere para percibirla al tiempo de la división social, (artículo 380). Queda la duda si procede respecto de los derechos sociales asignados al socio de tal manera que el acreedor pueda subastarlos;

Quinto: Características de la limitación: En una parte anterior de este trabajo habíamos indicado que las normas del artículo 2096 se aplican a las sociedades civiles y comerciales en tanto que las del 380 sólo a las comerciales, atendido el carácter supletorio del Código Civil. (Artículo $4^{\circ}$ de este cuerpo legal).

Esto nos lleva a delimitar más aún el tema en el sentido que el Código Civil permite el embargo, pero sólo respecto de las asignaciones que se hagan al deudor por cuenta de los beneficios sociales o de sus aportes o acciones. En tanto el Código de Comercio limita la acción a la retención de la parte del interés que el socio tuviere en la sociedad para percibirla al tiempo de la división social.

¿Significa ello que el Legislador no ha querido que se embarguen los derechos del socio, de tal manera que el acreedor no pueda intentar la subasta de ellos?.

Debo confesar que no tengo una respuesta categórica, la que podría obtenerse de una norma clara.

En favor de la posibilidad de embargo y posterior remate está el hecho de que no hay una norma clara que excluya el embargo a los "derechos sociales" para percibir, a través del remate, el pago actual, completo o no, de la acreencia. A mi modo de ver, el argumento dado por Alessandri, Somarriva y otros profesores, en el sentido que es inadmisible que por el remate un subastador pudiera introducirse en un pacto restringido a determinadas personales, choca con disposiciones legales que sí permiten la actividad de terceros en una sociedad de personas. Sin ahondar en el tema, encontramos esas posibilidades en la quiebra, la muerte de un socio, incapacidad sobreviniente de un socio, insolvencia y otros.

En abono a esta posición podemos razonar, (sólo para el caso de las sociedades comerciales), que el artículo 380 permite al acreedor pedir la retención de la parte del interés social... para percibirla al tiempo de la división social.

Esta disposición, a nuestro entender, indica a las claras, la posibilidad de hacer valer el derecho de prenda general sobre "la parte del interés social", que no es otro que el porcentaje que el socio-deudor tiene en la sociedad, con la sola salvedad que el acreedor podrá "percibirla al tiempo de la división social".

A la duda que nos viene a la mente, en el sentido de si dicho derecho del acreedor para percibir su acreencia al tiempo de la división social puede traspasarse a un 
tercero por la vía del remate, nuestra respuesta es positiva; en todo caso el adquirente deberá respetar el plazo para la recuperación de lo pagado.

Por otra parte, el socio-deudor queda inhibido de realizar cualquier acto jurídico que signifique menoscabo del derecho del acreedor.

Como vemos, esta disposición consagra claramente la posibilidad de retención o embargo de los derechos sociales.

En contra de la posibilidad de embargar juega un concepto ya comentado, pero que queremos explicitar. Decíamos que el Legislador puede consagrar una inembargabilidad en términos no sacramentales. ¿Podría pensarse que ése es el caso cuando, respecto de sociedades de personas sólo autoriza embargos o retenciones respecto de determinados bienes y no de otros? En el caso del Código de Comercio permite sólo la retención de la parte de interés que en ella tuviere para percibirla al tiempo de la división social, (lo cual excluye la recuperación inmediata del crédito) o en lo indicado por el Código Civil que permite sólo que se embarguen, a su favor, las asignaciones que se hagan a su deudor por cuenta de los beneficios sociales o de sus aportes o acciones.

Con los antecedentes que se entregan en este trabajo, cada uno sacará sus propias conclusiones. Nuestro pensamiento es el que los derechos o participación del deudor en una sociedad se encuentran afectos al derecho de prenda general en favor de los acreedores.

Pugna al criterio jurídico la posibilidad que el deudor pueda excluir de esa garantía general a determinados bienes por la sola circunstancia de constituir una sociedad con un testaferro.

Creemos que la redacción de los artículos que analizamos no puede interpretarse extensivamente cuando la norma en materia de embargo es la de aplicación restrictiva, atendida su naturaleza excepcional.

Nuestra estimación es que la disposición del inciso tercero, artículo 2096, que permite el embargo de las "asignaciones que se hagan al deudor... o de sus aportes o acciones" podría considerarse redundante ya que, al dar derecho al socio a retirarlas, ellas estarían ingresando al patrimonio del deudor.

Sexto: Preguntas que nos merece el tema: Frente a estas disposiciones, nuevamente se nos presentan algunas dudas, en relación a las cuales trataremos de dar nuestra opinión:

a) ¿Qué derechos conservativos tiene el acreedor?

b) ¿Pueden otros acreedores concurrir al reparto?

c) ¿Cuál es el plazo en el cual el acreedor podrá cobrar su acreencia? ¿Puede éste ser prorrogado por el deudor y qué posibilidad tiene el acreedor de poner aviso de término a la sociedad?

d) ¿Qué sucede si no hay utilidades o éstas no se reparten por determinación del administrador facultado para resolver sobre ello?

e) ¿Qué calificación jurídica podría darse al derecho del acreedor?

Veamos estos temas: 
a) ¿Qué derechos conservativos tiene el acreedor? Estimamos que el acreedor puede ejercer todos los derechos que la legislación común le entrega.

Pero, y siempre el pero, ¿hasta dónde puede llegar el ejercicio de esos derechos del acreedor?

Nos preguntamos esto porque es bien sabido que en las sociedades de personas, que se caracterizan por la cierta intimidad o confianza entre los socios, hay gestiones varias respecto de las cuales no queda constancia de ellas como podría ser, a vía de ejemplo, que el administrador de la entidad, que no sea el deudor, decide, conforme a las facultades que le han entregado, que las utilidades producidas se capitalizarán.

$\mathrm{O}$, como otro caso, que bienes sociales sean vendidos a precios viles, mediante contratos simulados.

En este orden de ideas, creemos que debe permitirse al acreedor el resguardo de sus derechos, interpretando en forma amplia las posibilidades de recurrir a las instituciones pertinentes en materias de derechos conservativos.

Ello, como contrapartida, significaría limitación de las atribuciones del administrador, no en el sentido de no poder ejercer facultades que le fueron otorgadas por los socios, sino que dar informe y voz al acreedor respecto de actos que pudieren significar desmedro de los derechos del socio deudor $y$, por ende, del acreedor.

Pero, en todo caso, la relación no podría ser directa entre "el administrador" y el "acreedor", sino que a través del Juez, quien, en definitiva, deberá regular estos derechos de resguardo.

En este tema, estimamos que, aún cuando se da al acreedor la posibilidad de "embargar a su favor las asignaciones que se hagan a su deudor...", este deudor podría ceder sus derechos sociales. Frente a esta posibilidad, cabría intentar la precautoria de prohibición, de celebrar actos y contratos respecto de los derechos que le corresponden al socio-deudor en la sociedad en la que participa.

En caso que el acreedor haya sido prudente, y se tome nota de la restricción al margen de la inscripción social, (en el caso de las comerciales), o de la escritura, (en las civiles), entendemos que si el socio-deudor cede sus derechos, la limitación o embargo deberá ser respetada por el cesionario.

b) ¿Pueden otros acreedores concurrir al reparto? A nuestro entender, la respuesta es positiva ya que los derechos del socio deudor se conservan en su patrimonio $y$, por consecuencia, están dentro del derecho de prenda general de los acreedores.

c) ¿Cuál es el plazo en el cual el acreedor podrá cobrar su acreencia? ¿Puede éste ser prorrogado por el deudor y qué posibilidad tiene el acreedor de poner aviso de término a la sociedad? En este punto debemos volver a la distinción establecida entre la normativa civil y la comercial.

La primera, permite que el acreedor pueda percibir, de inmediato, las asignaciones que se hagan a su deudor por cuenta de los beneficios sociales o de sus aportes o acciones.

En cambio, el Código de Comercio obliga al acreedor a esperar la división social. $Y$ esto para el caso que estimemos que los derechos sociales no son susceptibles de un 
remate inmediato. Lo primero nos lleva a otra duda: y si el acreedor, (en uso de los ya citados derechos de resguardo de su acreencia), pueda, en representación del deudor tomar la iniciativa de dar el aviso de término de la sociedad.

Una lógica común nos lleva a pensar que sí: pero, el criterio jurídico nos indica que ello no sería factible ya que el acreedor no tiene la representación del socio deudor.

¿Podría hacerlo el Juez? Con ciertas dudas pensamos que sí lo podría hacer, y damos una respuesta positiva porque pensamos que al quedar retenidos los beneficios del deudor queda fijada una fecha determinada en el contrato social para que el acreedor pueda cobrar su crédito.

Para resumir en esta materia, debemos volver a los dos artículos que estudian la materia que nos preocupa; el artículo 2096 del Código Civil autoriza el embargo de "las asignaciones que se hagan al deudor por cuenta de los beneficios sociales o de sus aportes o acciones.", y el artículo 380 que autoriza para "retener" "la parte de interés que en ella tuviere para percibirla al tiempo de la división social." Decimos que debemos repasar las diferencias entre ambas disposiciones, porque en la primera el acreedor podrá ir recuperando su crédito durante la vigencia de la sociedad, en tanto que, conforme a la segunda, deberá esperar hasta el tiempo de la división social, esto último que implica que deberá esperar la disolución y liquidación de la sociedad.

Esta norma tiene importancia porque las disposiciones del artículo 2096 se aplican a todas las sociedades de personas, civiles o comerciales, en tanto que las del artículo 380 no se aplican a las sociedades civiles.

Tenemos entonces que reiterar que, respecto de las sociedades comerciales se aplican dos normas, una, la del artículo 380. (que limita la acción del acreedor en el sentido de poder percibir su acreencia sólo para percibirla al tiempo de la división social), y la del artículo 2096. (que permite la recuperación paulatina del crédito por la vía del embargo de las asignaciones que se hagan al socio deudor).

¿En el caso de estas sociedades comerciales, cuál norma prima? A nuestro entender, nos inclinaríamos a aplicar el principio de la especialidad, es decir, que en este caso de sociedades comerciales, el acreedor sólo podrá percibir su crédito al momento de la liquidación social.

Esto a nuestro entender tiene importancia, porque si el acreedor sólo está autorizado para percibir al tiempo de la disolución de la sociedad, el deudor puede recibir las asignaciones o utilidades durante todo el período anterior a la muerte social.

d) ¿Qué sucede si no hay utilidades o éstas no se reparten por determinación del administrador facultado para resolver sobre ello? Pensamos que, desde el momento en que el administrador es notificado del embargo, (caso del artículo 2096), o de la retención, (situación del artículo 380), no podría capitalizar las utilidades que corresponde distribuir, ya que el acreedor adquirió el derecho a percibir los beneficios sociales en tiempo y forma.

\section{¿Qué opinan los estudiosos?}

En esta materia, sólo he encontrado la opinión de don Enrique Munita Becerra (consignada en un artículo publicado en la Revista de Derecho y Jurisprudencia, tomo 57, derecho p.p.. 89 a 103). 
Muy interesante todo el análisis del autor, profesor extraordinario de Derecho Comercial de la Universidad de Chile, que titula su estudio como "Embargabilidad del derecho social de un socio en una sociedad de personas, por un acreedor personal suyo."

Este autor llega a la conclusión de que "el acreedor investido de un título ejecutivo puede embargar y llegar, naturalmente, a subastar el derecho social del socio deudor, y el subastador podrá o a hacer liquidar parcialmente la sociedad a su favor y obtener lo que al socio cupiere o correspondiere en la sociedad a esa fecha, o bien, continuar en la sociedad como sucesor, subrogante o causahabiente del socio deudor embargado y así espera y recibe después lo que hubiere al tiempo de la división social, sin perjudicar ni al acreedor embargante que ha recibido el precio de la subasta, ni a la sociedad que prosigue su marcha, y tampoco se perjudicaría el mismo que ha preferido pagar aquel precio de la subasta y entrar en un negocio con legítimas expectativas de lucro, pero corriendo, al mismo tiempo, contingencias de pérdidas.

\section{¿Y la jurisprudencia?}

Tal como lo indicáramos al comenzar este trabajo, la jurisprudencia de los Tribunales de Justicia no es abundante. Diríamos que, en resumen, reiteran el principio base que "la sociedad es distinta de los socios individualmente considerados".

Veamos los fallos que hemos podido encontrar en las distintas publicaciones examinadas:

Primer Fallo: Publicado en la Gaceta del año 1927, Segundo Semestre, página 731 , sentencia N²174, Corte de Apelaciones de Santiago de fecha 19 de Noviembre de 1927. (Causa Gregorio Mauritz y otros con Arturo Terragno): Se trata de un fallo en el que se pronuncia respecto de una medida precautoria pedida por los acreedores de un socio. Se pretende mediante ella embargar un bien social, adquirido por la sociedad, no aportado.

Comentario: Nos llama la atención un aspecto del fallo de mayoría cuando consigna que la medida precautoria puede trabarse "... tanto en las sociedades como en el bien raiz embargado". Y ello porque se estaría autorizando una medida precautoria respecto de un bien social, en el cual sabemos que el socio no tiene ningún derecho por ser cosa ajena a él.

En la resolución judicial se declara que, si bien es posible el embargo de un bien, puede serlo sólo sobre la cuota que corresponde al demandado don Arturo Terragno, "tanto en las sociedades como en el bien raíz aludido."

Hay un voto disidente: “...la sociedad es una persona jurídica, distinta de los socios que la componen, y de ahi que el artículo 2091 establezca que los acreedores de un socio no tiene acción sobre los bienes sociales, sino en casos excepcionales, ninguno de los cuales es el que se trata en estos autos."

Segundo fallo. Publicado en la Gaceta del año 1905, Tomo Segundo, página 18, sentencia $\mathrm{N}^{2} 772$, que reproduce la sentencia del Juzgado de Chillán de 6 de Diciembre de 1904 y la de la I. Corte de Apelaciones de Talca de 9 de Octubre de 1905, (Causa Constant Fouquet con Pablo Lacassie y otros). 
Esta jurisprudencia se pronuncia respecto de una tercería interpuesta por don Luis Adduard en contra de don Constant Fouquet y Pablo Lacassie.

La historia es la siguiente: Constant Fouquet demanda a Pablo Lacassie por deudas de rentas de arrendamiento convenidas en un contrato que se celebró entre ambos por el cual el primero entregó a Pablo Lacassie diversas especies muebles destinadas al trabajo de barraca, obligándose este último al pago periódico de las rentas.

Posteriormente, Lacassie forma sociedad para el negocio de barraca con Luis Adduard, aportando las especies muebles. Más adelante, Lacassie y Adduard disuelven y liquidan la sociedad adjudicándose a éste el activo y pasivo de la sociedad.

En el juicio seguido por Fouquet se embargan las citadas especies muebles y Adduard inicia la tercería correspondiente.

En la resolución de la tercería se determina que entre Fouquet y Lacassie se celebró un contrato de compraventa de especies muebles, pese a que las partes no lo denominaron así; que en ese convenio no se estipuló pago a plazo como tampoco ninguna circunstancia que pudiera hacerlo presumir; y, que por el hecho que Lacassie aportara dichos bienes a una sociedad con un tercero, (Luis Adduard), en el cual no se expresó que la sociedad formada se hacía cargo de deuda alguna del aportante, la sociedad no estaba obligada al pago de las obligaciones del aportante, de tal manera que el acreedor no tenía acción respecto de los bienes sociales, sino la indirecta y subsidiaria de los artículos 2094 y 2096 del Código Civil. De esta manera, se hace lugar a la tercería.

Comentarios: La situación legal resuelta por la I. Corte de Apelaciones de Talca fue definida aplicándose las normas ya indicadas más arriba, en el sentido que "la sociedad es una persona jurídica distinta de sus socios", norma que se aplica, por consecuencia, a los patrimonios de cada uno de ellos. En la especie, los efectos del contrato suscrito entre Fouquet y Lacassie no pueden afectar al tercero, esto es, a Adduard, tanto más cuanto que en el contrato suscrito entre lo dos primeros no se expresa claramente el tipo de relación contractual pactada, el que fue estimado por la I. Corte como de compraventa;

Tercer Fallo: De la Corte Suprema, en sentencia de 30 de Julio de 1986, (R.t. 80, secc. $1^{\circ}$, pág. 47): "Es posible embargar las asignaciones a cuenta de los beneficios sociales o de sus aportes o acciones, como también le es permitido solicitar la retención de la parte de interés que en ella tuviere el socio deudor para percibirla al tiempo de la liquidación de la sociedad. Asimismo, pueden embargar los derechos de un socio en una sociedad de personas y subastarse, entendiéndose, sí, que el deudor no pierde la calidad de socio, ni la administración de la sociedad, si la tuviere, y el subastador sólo adquiere el derecho a percibir las asignaciones que se hagan al ejecutado a cuenta de los beneficios o sus aportes o acciones al momento de producirse la liquidación de la sociedad y división o liquidación del haber social, según se trate de sociedades civiles o comerciales;

Cuarto fallo: Corte de Concepción, Gaceta, año 1914, Julio-Agosto, № 392, página 1103: Disuelta una sociedad y mientras no se practique válidamente su liquidación, existe comunidad entre los ex-socios respecto de los bienes que fueron de aquella sociedad. 
Procede tercería de dominio de un socio para oponerse al embargo de la cosa común y pudiendo entonces el acreedor dirigir su acción sobre la parte o cuota que en la comunidad corresponde a su deudor, a fin de que se enajene sin previa liquidación, o exigir que con su intervención se liquide. (Artículo 524 del Código de Procedimiento Civil).

Quinto fallo: Corte de Apelaciones de La Serena, 4 de Diciembre de 1936, Gaceta 1937, Primer Semestre, № 33, página 156: El inciso tercero del artículo 2096 confirma la tesis que, por ser el patrimonio de la sociedad distinto del de los socios, éstos no llegan a ser dueños de las utilidades de la sociedad mientras no le han sido acordadas; dichas utilidades pasan a incrementar el patrimonio de esa persona jurídica; y

Otros fallos: En el mismo sentido general se pronuncian otros dos fallos tribunalicios que se han consultado, y que aparecen en las Gacetas de 1903 y 1908. (La de 1903, en el Tomo II, página 1134, sentencia N⒉312; y la de 1908, en el Tomo II, página 89 , sentencia $\mathrm{N}^{2} 56$ ).

\section{Conclusiones:}

Desde nuestro particular punto de vista pensamos que:

Primero: No es embargable el aporte introducido por el socio en la sociedad, una vez que se hayan cumplido con los requisitos legales del caso;

Segundo: En las sociedades civiles pueden embargarse las asignaciones que se hagan al deudor por cuenta de los beneficios sociales o de su aportes o acciones;

Tercero: En las sociedades comerciales se puede solicitar la retención de la parte de interés que el deudor tuviera en ellas para percibirla al tiempo de la división social y, además, embargar las asignaciones que se hagan al deudor por cuenta de los beneficios sociales o de sus aportes 0 acciones; $y$

Cuarto: En todos los casos, el acreedor puede rematar sus derechos y el tercero que subaste adquirirá el crédito con las limitaciones antes indicadas. 